\title{
Vascular remodelling in the pulmonary circulation after major lung resection
}

\author{
To the Editor:
}

Lung resection is a standard treatment in patients with clinical stages I and II and selected patients with stage IIIA nonsmall cell lung cancer [1]. Major lung resection (MLR), such as (bi)lobectomy or pneumonectomy, occasionally lead to pulmonary hypertension $(\mathrm{PH})$. Several studies report an increase in pulmonary artery pressures in about one-third of these patients up to 5 years postoperatively [2-4]. The development of PH after MLR may be explained simply by the fact that total cardiac output flows through a smaller vascular bed. Because there are no reports in the literature of histological studies performed after MLR, it remains unknown whether flow-induced structural changes in the remaining lung vasculature lead to progressive increases in pulmonary vascular resistance.

The aim of the current study was to determine whether an altered pulmonary blood flow per se is associated with phenotypic changes in the lung vasculature akin to PH. For the study, human lung tissue from the contralateral lung was obtained at least 2 years after pneumonectomy, bilobectomy or lobectomy of the left upper lobe. Healthy control tissue was from people who died acutely due to a traumatic cause, and these have described in earlier histopathological studies [5, 6]. Samples were obtained from the biobank of VUmc, Amsterdam, The Netherlands. For animal studies, wall thickness measurements in the unilateral lung of rats 6 weeks post-pneumonectomy were compared with those of sham-operated animals.

Evaluation of vasculopathy was performed according to previously described patterns [7]. Immunohistochemical staining with $\mathrm{Ki}-67$, histone $\mathrm{H} 3$ and cleaved caspase 3 was performed to determine proliferation and apoptosis of endothelial cells. For quantitative measurements, the thickness of the intimal and medial layers of arterioles (attached to four septal walls) was determined, and expressed as a percentage of the external diameter of these vessels. Vessels with an elliptical shape due to oblique sectioning were excluded.

Animal experiments were permitted by the Institutional Animal Care and Use of the VU University and conducted in accordance with the European Convention for the Protection of Vertebrate Animals used for Experimental and Other Scientific Purposes, and the Dutch Animal Experimentation Act (FYS12-18, FYS13-01). Sprague-Dawley rats ( $\mathrm{n}=4$ per group) underwent either pneumonectomy or sham operation. The animals were part of an earlier study, as described previously [8].

Lung tissue specimens from 13 patients with MLR and six controls were obtained. Control subjects died at an age of $36 \pm 4$ years old and were all male. MLR patients were $69 \pm 2$ years, and 10 out of 13 were male. 10 MLR patients had a known history of smoking and the average survival after surgery was $4.8 \pm 0.9$ years. The clinical history of four MLR patients was not available. Seven patients had received radiotherapy prior to MLR, three in combination with chemotherapy.

The predominant patterns observed in patients with MLR and absent in controls were thrombotic arteriopathy (46\%) and nonselective intimal fibrosis (23\%) (figure 1a). These patterns were not associated with the presence of inflammation. In half of the patients with thrombotic arteriopathy, vascular remodelling was mild with slight congestive features. In two patients, diffuse congestion was more prominent, and the last patient showed organising diffuse alveolar damage. All patients with nonspecific intimal fibrosis showed parenchymal intimal fibrosis, with involvement of the veins in two of these patients. Congestive vasculopathy was present both in patients with MLR and controls. In two patients with MLR, this was paired with intimal fibrosis in arterial, parenchymal and venous vessels, medial hyperplasia in bronchiolar arteries, and venous arterialisation. A very similar pattern was found in all

@ERSpublications

Major lung resection results in mild pulmonary vascular remodelling http://ow.ly/JRvW30doTC0

Cite this article as: Rol N, Happé C, Beliën JAM, et al. Vascular remodelling in the pulmonary circulation after major lung resection. Eur Respir J 2017; 50: 1700806 [https://doi.org/10.1183/13993003.00806-2017]. 
a)

\begin{tabular}{lccc} 
Type of arteriopathy & Control \% & MLR \% & p-value \\
\hline Plexogenic & $0(0)$ & $0(0)$ & 1.00 \\
Thrombotic & $0(0)$ & $6(46)$ & 0.11 \\
Hypoxic & $0(0)$ & $1(8)$ & 1.00 \\
$\begin{array}{l}\text { Congestive } \\
\text { Nonselective }\end{array}$ & $3(50)$ & $3(23)$ & 0.32 \\
$\begin{array}{l}\text { intimal fibrosis } \\
\text { Other (bleeding, }\end{array}$ & $0(0)$ & $3(23)$ & 0.52 \\
$\begin{array}{l}\text { pneumonitis, } \\
\text { pneumonia) }\end{array}$ & $2(33)$ & $6(46)$ & 1.00 \\
\end{tabular}

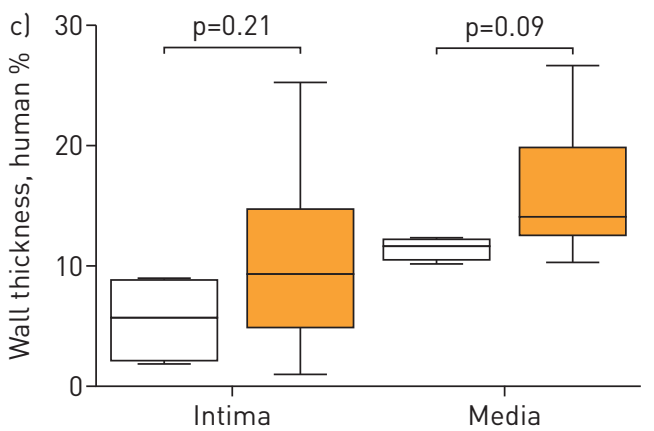

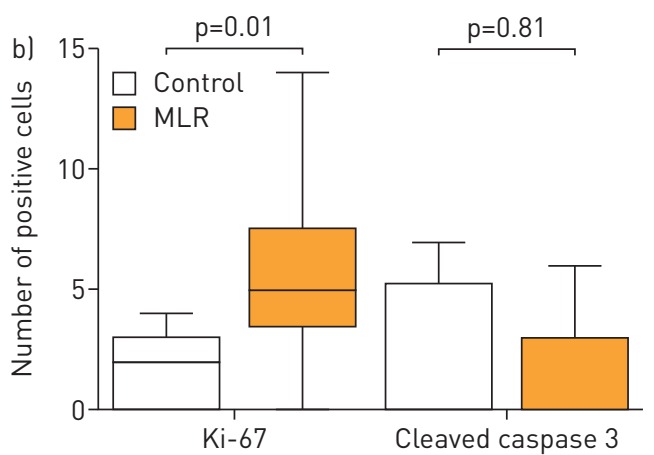

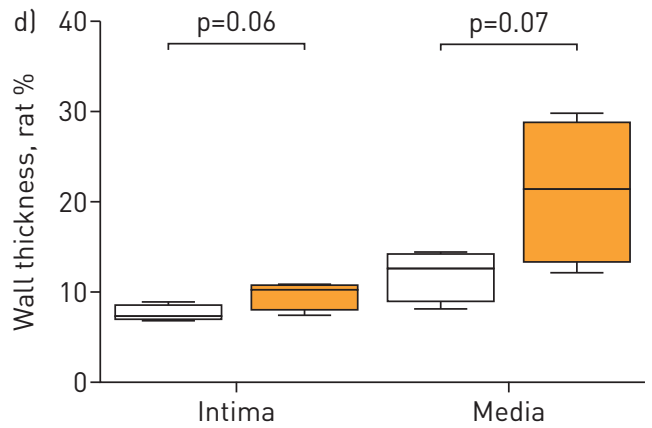

FIGURE 1 a) Type of arteriopathy in major lung resection (MLR) and control lung tissue scored quantitatively, p-values calculated with Fisher's exact test. b) number of positively stained endothelial cells for Ki-67 and cleaved caspase 3. c) Intimal and medial wall thickness in human and d) rat, expressed as percentage of outer diameter of the vessel. Data are reported as box and whisker plots, minimum to maximum. For statistical analysis unpaired t-tests (parametric data) and Mann-Whitney tests (non-parametric data) were used.

controls with congestive structural changes. There was no conclusive diagnosis for the other two patients with MLR with congestive vasculopathy.

The number of endothelial cells positively staining for the proliferation marker Ki-67 was higher in the MLR group ( $p=0.01$ ) (figure $1 b)$, and did not correlate with inflammation $(p=0.50)$. Histone H3 showed a similar pattern, although this was not statistically significant $(p=0.18)$. No differences were found for cleaved caspase 3 ( $\mathrm{p}=0.81$ ) (figure $1 \mathrm{~b})$.

In the human pulmonary vasculature, the outer diameter of the arterioles ranged between 27 and $178 \mu \mathrm{m}$, with a mean distance of 69 and $76 \mu \mathrm{m}$ in control and patients with MLR, respectively $(\mathrm{p}=0.33)$. There was no significant increase in the intima thickness in MLR lung tissue, but the media showed a tendency towards thickening (figure 1c). Thickening of the intimal and medial wall was not different in participants with and without inflammation. In rats, the outer diameter was $40 \pm 1.3 \mu \mathrm{m}$ (sham) and $43 \pm 2.6 \mu \mathrm{m}$ (MLR) $(\mathrm{p}=0.32)$. Both vascular layers showed a tendency towards thickening (figure $1 \mathrm{~d}$ ).

The small cohort and random selection of tissue blocks limits the generalisation of our findings. Other limitations are possible confounding factors, including differences in age, smoking history or cancer treatment. Thickening of the intima is often seen in older subjects [9] and smokers [10,11]. Both features apply to patients undergoing MLR for lung cancer. Chemotherapy and radiotherapy are also associated with vascular, mostly intimal, remodelling $[12,13]$. The increased presence of inflammation we found in patients with MLR was probably related to illness at the end of life. However, inflammation was not associated with vasculopathy patterns or proliferation, suggesting that these changes were not consequences of inflammatory activity. We observed increased Ki-67 staining in the MLR group without changes in cleaved caspase 3, indicating ongoing proliferation in the pulmonary vasculature. However, we could not link this observation to a greater intimal thickness.

We hypothesise that pulmonary hyperflow per se could induce remodelling in the pulmonary vasculature, even when no PH develops. Indeed, six of our patients with MLR showed thrombotic arteriopathy, while healthy controls did not present this predominant pattern. Intimal and medial thickness was not changed in human and rat lungs. Finally, patients with MLR showed increased proliferation, without changes in 
apoptosis. Surprisingly, we observed congestive arteriopathy in half of the control lung samples, indicating that these findings are common and probably nonspecific rather than related to hyperflow.

The findings in our focused study of 13 patients after MLR imply that vascular changes in PH are perhaps partially explained by altered pulmonary blood flow, but further research is needed in a larger cohort with more tissue samples, in order to study which additional stimuli are needed to induce $\mathrm{PH}$.

Nina Rol ${ }^{1}$, Chris Happé ${ }^{1}$, Jeroen A.M. Beliën $\circledast^{2}$, Frances S. de Man ${ }^{1}$, Nico Westerhof ${ }^{1}$, Anton Vonk-Noordegraaf ${ }^{1}$, Katrien Grünberg ${ }^{3}$ and Harm J. Bogaard ${ }^{1}$

${ }^{1}$ Dept of Pulmonology, VU University Medical Center, Amsterdam, The Netherlands. ${ }^{2}$ Dept of Pathology, VU University Medical Center, Amsterdam, The Netherlands. ${ }^{3}$ Dept of Pathology, Radboudumc, Nijmegen, The Netherlands.

Correspondence: Harm Jan Bogaard, Dept of Pulmonology, VU University Medical Center, De Boelelaan 1117, 1081 HZ, Amsterdam, The Netherlands. E-mail: HJ.Bogaard@vumc.nl

Received: Jan 172017 | Accepted after revision: May 312017

Support statement: This study was supported by a grant from Longfonds, grant \#3.3.12.036. Funding information for this article has been deposited with the Crossref Funder Registry.

Conflict of interest: Disclosures can be found alongside this article at erj.ersjournals.com

\section{References}

1 Manser R, Wright G, Hart D, et al. Surgery for early stage non-small cell lung cancer. Cochrane Database Syst Rev 2005; CD004699.

2 Deslauriers J, Ugalde P, Miro S, et al. Adjustments in cardiorespiratory function after pneumonectomy: results of the pneumonectomy project. J Thorac Cardiovasc Surg 2011; 141: 7-15.

3 Foroulis CN, Kotoulas CS, Kakouros S, et al. Study on the late effect of pneumonectomy on right heart pressures using Doppler echocardiography. Eur J Cardiothorac Surg 2004; 26: 508-514.

4 Potaris K, Athanasiou A, Konstantinou M, et al. Pulmonary hypertension after pneumonectomy for lung cancer. Asian Cardiovasc Thorac Ann 2014; 22: 1072-1079.

5 Overbeek MJ, Mouchaers KT, Niessen HM, et al. Characteristics of interstitial fibrosis and inflammatory cell infiltration in right ventricles of systemic sclerosis-associated pulmonary arterial hypertension. Int $J$ Rheumatol 2010: 2010

6 Overbeek MJ, Boonstra A, Voskuyl AE, et al. Platelet-derived growth factor receptor-beta and epidermal growth factor receptor in pulmonary vasculature of systemic sclerosis-associated pulmonary arterial hypertension versus idiopathic pulmonary arterial hypertension and pulmonary veno-occlusive disease: a case-control study. Arthritis Res Ther 2011; 13: R61.

7 Grünberg K, Mooi WJ. A practical approach to vascular pathology in pulmonary hypertension. Diagn Histopathol (Oxf) 2013; 19: 298-310.

8 Happe CM, De Raaf MA, Rol N, et al. Pneumonectomy combined with SU5416 induces severe pulmonary hypertension in rats. Am J Physiol Lung Cell Mol Physiol 2016; 310: L1088-L1097.

9 Wagenvoort CA, Wagenvoort N. Age changes in muscular pulmonary arteries. Arch Pathol 1965; 79: 524-528.

10 Chiu JJ, Chien S. Effects of disturbed flow on vascular endothelium: pathophysiological basis and clinical perspectives. Physiol Rev 2011; 91: 327-387.

11 Santos S, Peinado VI, Ramirez J, et al. Characterization of pulmonary vascular remodelling in smokers and patients with mild COPD. Eur Respir J 2002; 19: 632-638.

12 Weintraub NL, Jones WK, Manka D. Understanding radiation-induced vascular disease. J Am Coll Cardiol 2010; 55: $1237-1239$.

13 Sanchez-Gonzalez PD, Lopez-Hernandez FJ, Lopez-Novoa JM, et al. An integrative view of the pathophysiological events leading to cisplatin nephrotoxicity. Crit Rev Toxicol 2011; 41: 803-821. 